\title{
The Effect of Chia Seeds (Salvia hispanica L.) Addition on Quality and Nutritional Value of Wheat Bread
}

\author{
Daria Romankiewicz, ${ }^{1}$ Waleed Hameed Hassoon, ${ }^{2,3}$ \\ Grażyna Cacak-Pietrzak, ${ }^{1}$ Małgorzata Sobczyk, ${ }^{1}$ Magdalena Wirkowska-Wojdyła, ${ }^{4}$ \\ Alicja Ceglińska, ${ }^{1}$ and Dariusz Dziki ${ }^{3}$ \\ ${ }^{1}$ Division of Cereal Technology, Faculty of Food Sciences, Warsaw University of Life Sciences, Nowoursynowska 159C, Warsaw, Poland \\ ${ }^{2}$ College of Food Sciences, Department of Food Technology, Al-Qasim Green University, Babylon, Iraq \\ ${ }^{3}$ Department of Thermal Technology and Food Process Engineering, Faculty of Production Engineering, University of Life Sciences, \\ Doświadczalna Str. 44, 20-280 Lublin, Poland \\ ${ }^{4}$ Department of Chemistry, Faculty of Food Sciences, Warsaw University of Life Sciences, Nowoursynowska 159C, Warsaw, Poland
}

Correspondence should be addressed to Dariusz Dziki; dariusz.dziki@up.lublin.pl

Received 22 October 2017; Accepted 5 December 2017; Published 31 December 2017

Academic Editor: Hüseyin Erten

Copyright ( 2017 Daria Romankiewicz et al. This is an open access article distributed under the Creative Commons Attribution License, which permits unrestricted use, distribution, and reproduction in any medium, provided the original work is properly cited.

\begin{abstract}
The aim of the study was to analyze and characterize the influence of chia seeds (CS) addition (0,2, 4, 6, and $8 \%)$ on wheat bread properties. Bread properties that underwent evaluation included chemical composition, fatty acid composition, total phenolics content, volume, baking losses, crumb texture, and color and sensory analysis. The addition of CS decreased baking losses and the volume of bread. The color of the crumb with CS was much darker as compared with the control sample. The texture analysis showed that the CS caused a decrease in the hardness of the crumb. Most importantly, the addition of CS increased the nutritional value of the bread. Bread with CS contained more dietary fiber and mineral components. Moreover, it has been observed that in comparison to the control product bread with CS was characterized by a rich fatty acids composition and higher level of phenolic compounds. Most importantly, the results showed that the substitution of wheat flour with chia seeds up to $6 \%$ did not negatively affect the final product acceptance.
\end{abstract}

\section{Introduction}

Chia is an annual herbaceous plant that belongs to the Lamiaceae family. It comes from southern Mexico and northern Guatemala. Despite the high nutritional values, the chia seeds are rarely used in food production. The seeds contain fat that is a good source of omega 3 and omega 6 fatty acids. In addition, the seeds have a relatively high content of protein of high biological value. They are rich in the essential amino acids, particularly leucine, lysine, isoleucine, and valine $[1,2]$. Therefore, the seeds can be a complement of cereal proteins that are deficient in the essential amino acids. Additionally, chia seeds have a high dietary fiber content, which is characterized by a high water absorption and the ability to form aqueous solutions with increased viscosity. This helps to better keep the water in the final product, so that it can stay fresh longer [3]. What is more is that chia seeds are an important source of natural antioxidants such as tocopherols, sterols, carotenoids, phenolic compounds including chlorogenic and caffeic acid, quercetin, myricetin, and kaempferol $[4,5]$. In recent years, the European Parliament approved chia seeds as a novel food. This resulted in an increase in use of chia seeds in food production [6]. Recent studies have shown that chia seeds can be used to produce food products such as biscuits [7], pasta [8], and especially bread [9-11]. There are several works concerning the influence of chia addition on bread texture. Zettel et al. [12] studied the effects of chia incorporated in wheat bread dough in the form of gel and proved that chia addition reduced the bread firmness. Coelho and Salas-Mellado [10] found that bread 
crumb containing whole chia seeds was softer in contrast to the one with chia flour. However, this tendency was not confirmed by Iglesias-Puig and Haros [13]. Costantini and others [14] observed that the addition of chia flour increased the total antioxidant capacity of wheat breads. However, they used only one share of chia flour addition (10\%). Since in the present studies different shares and forms of chia were added to bread recipes, it is difficult to compare the obtained results. Therefore, the aim of the present study was to determine the possibilities of using chia seeds in the production of the wheat bread. Furthermore, the aim of the study was to determine the impact of chia seeds on texture, total phenolics content, antioxidant properties, and fatty acids profile of wheat bread.

\section{Materials and Methods}

2.1. Material and Reagents. The research material was wheat flour (WF) type 550 produced by Polskie Młyny S. A. (Poland) and chia seeds were obtained from Bio Company Pulst J. M. (Poland). The other ingredients used in the production of bread were salt produced by Cenos Sp.zo.o. (Poland) and instant dry yeasts produced by Dr. Oetker Sp.zo.o. (Deutschland), bought in the local market. The chia seeds were ground before analysis by using the laboratory hammer mill POLYMIX-Micro-Hammermill MFC [15]. The obtained flour (particles below $0.3 \mathrm{~mm}$ ) was used for analysis.

2.2. Chemical Composition of the Material. During the study an analysis was performed of chemical composition of wheat flour, chia seeds, and the obtained breads. Water content was determined using drying method [16]. Total protein content was determined by Kjeldahl method [17] $(N \times 5.7$ and $N \times 6.23$ for wheat flour and chia seed, resp. [2]). The ash content was evaluated through incineration of the samples in a muffle furnace at $900^{\circ} \mathrm{C}$ for 60 minutes [18]. The chia seeds were ground before analysis. The obtained flour (particles below $0,3 \mathrm{~mm}$ ) was used for analysis. The total dietary fibre content was also measured using an enzymatic-gravimetric method [19]. The ground sample was digested with a thermostable alpha-amylase, protease, and amyloglucosidase in order to remove the protein and starch present in the sample. Then, $95 \mathrm{~g} / \mathrm{L}$ ethanol was added in order to precipitate the soluble fiber. The resulting precipitate was filtered and was rinsed with ethanol and acetone. Then, it was dried at $105^{\circ} \mathrm{C}$ until regular mass. In the next stage the sediments were analyzed in terms of total protein and ash content. The total dietary fibre (TDF) content was calculated using formula (1): TDF = $(R-P-A) / \mathrm{SW}$, where $R$ is average weight of the sediment (mg); $P$ is average weight of protein (mg); $A$ is average weight of ash (mg); SW is average sample weight $(\mathrm{mg})$. Total fat content was measured using a solvent extraction method in a Soxhlet's extractor [20].

2.3. Fatty Acids Composition. Fatty acids composition of raw materials and bread was performed using a gas chromatography (GS). Fatty acid methyl esters were prepared in accordance with European Standard [21]. An YL6100 GC chromatograph was equipped with a flame ionization detector. It had also capillary column (BPX-70). Parameters used the column length $60 \mathrm{~m}$, internal diameter $0.2 \mathrm{~mm}$, and film thickness $0.25 \mu \mathrm{m}$. The conditions separation fatty acid methyl esters were as follows: initial temperature of $60^{\circ} \mathrm{C}$ for $5 \mathrm{~min}$, which was then increased by $10^{\circ} \mathrm{C}$ per minute to $180^{\circ} \mathrm{C}$ and a further increase of $180^{\circ} \mathrm{C}$ to $230^{\circ} \mathrm{C}$ followed by $3^{\circ} \mathrm{C}$ per minute. The final temperature $230^{\circ} \mathrm{C}$ was maintained for 15 minutes. The temperature of the split injector was $225^{\circ} \mathrm{C}$. The temperature of the detector was $250^{\circ} \mathrm{C}$. Nitrogen was used as the carrier gas (flow rate $-1 \mathrm{~mL}$ per minute). The fatty acids were identified using standard lipid purchased from Sigma Aldrich.

2.4. Total Phenolics Content and Ability to Neutralize Free Radicals. Extract preparation $500 \mathrm{mg}$ of samples (flour form raw materials or bread) was extracted with $5 \mathrm{ml}$ of $\mathrm{MeOH}$ : water $(1: 1, \mathrm{v} / \mathrm{v}, \mathrm{pH}=1)$ mixture (chemical extract, $\mathrm{CE}$ ) or PBS buffer (buffer extract, BE). Sample was shaken for $30 \mathrm{~min}$ and centrifuged at $(13000 \mathrm{~g}, 10 \mathrm{~min})$. Collected supernatants were used for biochemical analysis. The assay was performed by Folin-Ciocalteu's method [22] with slight modification [23].

Ability to neutralize free radicals (ABTS) was performed using the method in which the $\mathrm{ABTS}^{\bullet}$ radicals were reduced by the antioxidants containing extracts of the analyzed samples [24]. The ability to neutralize free radicals was expressed as EC50, extract concentration corresponding to $50 \%$ reduction of the initial concentration of the synthetic $\mathrm{ABTS}^{\bullet}$ radical.

2.5. Breads Preparation. The bread dough was prepared using a direct method (Table 1) [25]. The wheat flour was replaced with chia seeds (CS) at 2, 4, 6, and $8 \%$ (CS2, CS4, CS6, and CS8, resp.). The wheat flour and wheat flour with the addition of CS were analyzed using the farinograph test to determine the amount of added water. The components were mixed in a laboratory mixer (SP 800A, Sweden). After proofing, the dough was divided into $250 \mathrm{~g}$ pieces. The pieces were molded by hand and then put in the molds (size about $10 \times 10 \times$ $10 \mathrm{~cm}$ ). The molded doughs were proofed again for $60 \mathrm{~min}$. The breads were baked in an electric oven (Sveba Dahlen, Sweden). After baking they were removed from the molds and weighted. After cooling, the loaves were packed into polyethylene bags and stored for $24 \mathrm{~h}$ at $20^{\circ} \mathrm{C}$. The bread yield (BY), representing the amount of bread obtained from $100 \mathrm{~g}$ of flour, was calculated as follows:

$$
\mathrm{BY}=\frac{(c * w)}{d},
$$

where $d$ is a weight of dough portion before baking, $c$ is the mass of bread after cooling ( $\mathrm{g}$ ), and $w$ is a dough yield. Besides, the baking losses were calculated.

The dough yield $(w)$ was calculated as follows:

$$
w=100 * \frac{a}{m},
$$

where $a$ is a mass of dough and $m$ is a mass of flour (g).

2.6. Physical Properties of Bread. The physical properties of bread were determined 24 hours after baking. The following parameters were determined: bread volume, density, porosity, and crumb color. 
TABLE 1: Bread making method.

\begin{tabular}{|c|c|c|c|c|c|}
\hline Sample designation & $\mathrm{PK}$ & CS2 & CS4 & CS6 & CS8 \\
\hline \multicolumn{6}{|l|}{ Recipe for dough } \\
\hline Flour & Wheat & Wheat & Wheat & Wheat & Wheat \\
\hline Chia seeds & - & $2 \%$ & $4 \%$ & $6 \%$ & $8 \%$ \\
\hline Salt & & \multicolumn{4}{|c|}{$1.52 \%$} \\
\hline Instant yeast & & \multicolumn{4}{|c|}{$1.02 \%$} \\
\hline Water & & \multicolumn{4}{|c|}{ Up to consistency of $350 \mathrm{BU}$} \\
\hline Dough mixing time/mixing speed & & \multicolumn{4}{|c|}{$4 \mathrm{~min} / 235 \mathrm{rpm}$} \\
\hline Dough fermentation conditions & & \multicolumn{4}{|c|}{$\begin{array}{l}30^{\circ} \mathrm{C}, \mathrm{RH} 75 \%, 90 \mathrm{~min} \text { (transfixion } \\
\text { after } 60 \mathrm{~min} \text { ) }\end{array}$} \\
\hline Dough proofing conditions & & \multicolumn{4}{|c|}{$30^{\circ} \mathrm{C}, \mathrm{RH} 75 \%, 60 \mathrm{~min}$} \\
\hline Baking conditions & & \multicolumn{4}{|c|}{$230^{\circ} \mathrm{C}, 30 \mathrm{~min}$} \\
\hline
\end{tabular}

${ }^{*}$ PK, control bread, CS2, CS4, CS6, and CS8, bread with 2, 4, 6, and 8\% of chia seeds, respectively, RH, relative humidity, and BU, Brabender units.

The volume of a bread loaf was determined using a 3D scanner (NextEngine, USA). The volume of the finished bread model was calculated using a computer program MeshLab. The bread volume was expressed in $\mathrm{cm}^{3}$ and converted to $100 \mathrm{~g}$ of bread.

The measurement of crumb porosity was performed by determination of the differences between the volumes of uncompressed and compressed crumb, which was devoiced of pores by kneading. The $27 \mathrm{~cm}^{3}$ volume cylinders were cut from the bread crumb and were kneaded. Then, they were immersed in oil in order to determine the volume [25].

The crumb color was determined using the Chromameter Minolta (CR-200, Japan). The trichromatic colorimetric method was used based on a system of color $L^{*}, a^{*}$, and $b^{*}$. According to the International Commission on Illumination parameter $L^{*}$ was responsible for lightness. The values $+a^{*}$, $-a^{*},+b^{*}$, and $-b^{*}$, respectively, represented the colors: red, green, yellow, and blue. The total crumb color differences between bread crumb with chia seeds addition and control bread sample were calculated using the common known formula:

$$
\Delta E=\sqrt{\left(L_{1}-L_{2}\right)^{2}+\left(a_{1}-a_{2}\right)^{2}+\left(b_{1}-b_{2}\right)^{2}},
$$

where $\Delta E$ is absolute color difference, $L_{1}, a_{1}$, and $b_{1}$ are compositional crumb color of control bread, and $L_{2}, a_{2}$, and $b_{2}$ are compositional crumb color of bread with chia seeds addition.

2.7. Bread Crumb Texture. The measurement was performed using the Texture Analyzer type TA.XT2i (Stable Microsystems, Surrey, UK). The assay relied on a dual compression of the crumb sample (thickness of slices $-25 \mathrm{~mm}$ ). A cylindrical mandrel with a $25 \mathrm{~mm}$ diameter was used in the measurement. The speed test was $1 \mathrm{~mm} / \mathrm{s}$. $40 \%$ penetration of the sample was applied, with a 45-second break between the first and second pressure. Based on the graphs the following parameters of bread crumb texture were determined: hardness, springiness, cohesiveness, gumminess, and chewiness [26].
2.8. Sensory Evaluation of Bread. A team of 68 trained panelists conducted a sensory evaluation of bread 24 hours after the baking. The analysis was performed at Warsaw University of Life Sciences in Warsaw, Poland, in a stable temperature and light. Bread was cut into slices. Samples were scored using a five-point hedonic scale, where 1 is dislike extremely, 2 is dislike moderately, 3 is neither like or dislike, 4 is like moderately, and 5 is like extremely [27] according to the appearance, taste, smell, color, texture, and overall desirability.

2.9. Statistical Analysis. All tests were performed in four replicates. The results were statistically analyzed in the Statistica 10. One-way analysis of variance (ANOVA) was made with significance level $\alpha=0.05$. The homogenous groups were determined by Tukey's test.

\section{Results and Discussion}

3.1. Physicochemical Properties of Raw Materials. Table 2 presents the content of selected chemical components in the raw material used in the study. In comparison with the wheat flour, chia seeds contained approx. 2 times higher protein content, approx. 20 times higher total fat content, approx. 13 times higher total dietary fiber content, and approx. 8 times higher mineral components content. It is a confirmation of their high nutritional value. It is also shown by Pizarro et al. [28] and Valdivia-López and Tecante [29] and Hruškovà and Švec [11]. The percentage share of fatty acids present in the wheat flour and chia seeds was shown in Table 2. In the fat isolated from the wheat flour and chia seeds the following acids were present: palmitic, stearic, oleic, linoleic, and $\alpha$ linolenic acid. Linoleic acid was predominant in wheat flour and accounted for more than half of the total fatty acids present. The $\alpha$-linolenic acid predominated in chia seeds. It was discovered that chia seeds' fat content contained 4 times less saturated acids than the fat from the wheat flour. The share of valuable polyunsaturated fatty acids in the chia seeds' fat amounted to approx. 90\%. In comparison to wheat flour, chia seeds had the total phenolic content approx. 6 times 
TABLE 2: Chemical composition, fatty acids profile, total phenolics content (TPC), and antioxidant activity (ABTS) of raw materials.

\begin{tabular}{lcc}
\hline Raw material & Wheat flour & Chia seeds \\
\hline Water content [\%] & $13.8 \pm 0.05$ & $8.9 \pm 0.04$ \\
Protein content [\%] & $10.9 \pm 0.30$ & $25.7 \pm 0.41$ \\
Ash content [\%] & $0.48 \pm 0.03$ & $4.05 \pm 0.08$ \\
Dietary fibre content [\%] & $3.13 \pm 0.11$ & $42.9 \pm 0.94$ \\
Total fat content [\%] & $1.5 \pm 0.10$ & $31.4 \pm 0.11$ \\
The fatty acid profile [\%] & & \\
$\quad$ Palmitic acid & $16.20 \pm 0.30$ & $4.88 \pm 0.41$ \\
$\quad$ Stearic acid & $0.77 \pm 0.05$ & $1.60 \pm 0.17$ \\
$\quad$ Oleic acid & $11.0 \pm 0.12$ & $3.9 \pm 0.23$ \\
$\quad$ Linoleic acid & $67.90 \pm 0.42$ & $16.93 \pm 0.36$ \\
$\quad \alpha$-Linolenic acid & $4.14 \pm 0.34$ & $72.68 \pm 1.17$ \\
TPC [mg GAE/g d.m.] & $0.86 \pm 0.05$ & $5.78 \pm 0.26$ \\
ABTS [EC (mg d.m./ml) ] & $729.5 \pm 12.8$ & $80.24 \pm 8,32$ \\
\hline
\end{tabular}

higher and were characterized by approx. 9 times higher ability to neutralize free radicals.

3.2. Baking Results. The yield of bread ranged from $137.6 \%$ to $140.7 \%$ (Table 3 ). The addition of $4 \%$ and $6 \% \mathrm{~g}$ of CS caused a significant reduction of bread yield as compared to the control sample. The baking loss changed from $7.7 \%$ to $9.5 \%$. The addition of $6 \%$ and $8 \%$ of CS significantly reduced the value of the baking loss as compared to other breads. Similar relationship was observed in studies of other authors $[9,10$, 28]. Chia seeds contain a lot of dietary fiber and mucilage, which combines free water and prevents its evaporation during the process of baking [12].

3.3. Analysis of the Physical Properties of Bread. The loaf volume of bread decreased with the addition of CS (average from $372.1 \mathrm{~cm}^{3} / 100 \mathrm{~g}$ for control bread to $316.2 \mathrm{~cm}^{3} / 100 \mathrm{~g}$ for CS8). There was no significant effect of the addition of chia seeds on porosity of the bread crumb. Coelho and Salas-Mellado [10] produced bread with $11 \%$ addition of the hydrated chia seeds. The authors showed that the enriched bread had a significantly smaller volume than the control bread. The chia seeds addition caused a decrease in the share of gluten in the bread' dough. The structure of the dough could be weakened during the production process. As a result, ability could be reduced to maintain $\mathrm{CO}_{2}$ during proofing and baking.

The values of the bread crumb color parameters were shown in Table 3. The component of color $\left(L^{*}\right)$ responsible for the lightness of the bread crumb changed from 67.3 to 75.7. Other color components: $a^{*}$ and $b^{*}$ were, respectively, from -0.7 to -0.4 and from 11.0 to 13.6. The breads with chia seeds had a significantly lower value of $L^{*}$ and $b^{*}$ than the control bread. This indicated that the bread crumb with addition of chia seeds had a darker color and the share of yellow was smaller as compared with the control sample. On the basis of received value, according to the criteria of the International Commission on Illumination, the total difference of color $(\Delta E)$ was classified. It was assumed that the value of $\Delta E$ in the range of $0-2.0$ was unrecognizable; the range between
2.0 and 3.5 was possible to recognize by an inexperienced observer, and with the value above 3.5 the difference of color was clear [29]. The total difference of color between the sample bread crumb and bread with chia seeds addition was above 3.5 (regardless of the chia seeds dosage). This means that the color of the bread crumb with chia addition was significantly different from the control bread crumb color. During baking process, temperature in the crumb of bread does not reach $100^{\circ} \mathrm{C}$, while in the crust of bread it is above $100^{\circ} \mathrm{C}$. Mailard's reaction that influences the color of the product took place only in the crust of bread [9]. The color of the bread crumb mainly depends on raw materials used. The color of chia seeds can vary from a light cream to a dark grey [5]. Chia seeds are rich in phenolic compounds such as caffeic acid, chlorogenic acid, ferulic acid, p-coumaric acid, 7-hydroxycoumarin, catechol, quercetin, quercetin-3glucoside, and kaempferol, which besides their antioxidant properties affect the color of the bread [13].

3.4. Bread Crumb Texture. The texture profile analysis parameters were shown in Table 3. The hardness of the bread crumb is a parameter that is most often determined in bread texture studies. It is described as the maximum force that was recorded during the first crumb kneading [26]. Hardness of the wheat bread crumb without additives amounted to 13.0 N. For CS4, CS6, and CS8 samples slight but significant reduction of this parameter was observed to the level of 11.0 N. CS addition weakens the gluten matrix and causes the weakening of the crumb cell structure; thus the obtained breads had lower volume. The lower volume of bread usually causes an increase of crumb hardness. From the other hand the decrease in force required to compress the bread slice was observed for CS6 and CS8 crumb samples, which means that crumb hardness was decreased. This may be due to chemical composition of CS and especially gum and fat content which probably caused a decrease of bread hardness. Similar tendency was observed when flaxseed flour (which has a similar composition to chia) was incorporated into wheat flour [30].

The springiness of the bread crumb ranged from 0.94 to 0.95 , while the cohesiveness of the bread crumb ranged from 0.66 to 0.71 . The springiness of bread is a parameter describing a degree to which crumb returns to its original shape from before compression. The cohesiveness parameter is determined on the basis of work done during the compression of the crumb during the first and second kneading $[26,31]$. CS addition had no significant influence on these parameters.

The gumminess of the wheat bread crumb without additives was $9.07 \mathrm{~N}$. The breads with CS addition had less gummy crumb than the control sample. The gumminess is determined by the force required to fragment the product [26]. The increase of bread crumb gumminess is received unfavorably by the consumers [32].

The study shows that the bread with chia seeds addition requires less work during the fragmentation of the product (from $7.31 \mathrm{~N} \cdot \mathrm{mm}$ to $7.83 \mathrm{~N} \cdot \mathrm{mm}$ ) as compared to the control bread, for which the highest chewiness was obtained (9.04 $\mathrm{N} \cdot \mathrm{mm}$ ). The studies of Iglesias-Puig and Haros [13] also 
TABLE 3: Characteristics of obtained breads.

\begin{tabular}{|c|c|c|c|c|c|}
\hline \multirow{2}{*}{ Parameter } & \multicolumn{5}{|c|}{ Sample } \\
\hline & $\mathrm{PK}^{1}$ & $\mathrm{CS} 2$ & CS4 & CS6 & CS8 \\
\hline Water absorption of flour (\%) & $59.8^{\mathrm{a}} \pm 0.22$ & $59.6^{\mathrm{a}} \pm 0.15$ & $59.7^{\mathrm{a}} \pm 0.10$ & $59.5^{\mathrm{ab}} \pm 0.13$ & $59.2^{\mathrm{ab}} \pm 0.31$ \\
\hline Bread yield [\%] & $140.18^{\mathrm{b}} \pm 0.59$ & $140.72^{\mathrm{b}} \pm 0.47$ & $138.83^{\mathrm{a}} \pm 0.54$ & $138.33^{\mathrm{a}} \pm 0.56$ & $137.62^{\mathrm{a}} \pm 0.56$ \\
\hline Baking loss [\%] & $9.10^{\mathrm{b}} \pm 0.32$ & $9.50^{\mathrm{b}} \pm 0.41$ & $9.15^{\mathrm{b}} \pm 0.29$ & $7.72^{\mathrm{a}} \pm 0.36$ & $7.84^{\mathrm{a}} \pm 0.36$ \\
\hline Volume $\left[\mathrm{g} / \mathrm{cm}^{3}\right]$ & $372.1^{\mathrm{d}} \pm 2.6$ & $361.1^{c} \pm 6.0$ & $340.8^{\mathrm{b}} \pm 5.6$ & $323.8^{\mathrm{a}} \pm 4.7$ & $316.2^{\mathrm{a}}+6.3$ \\
\hline Crumb porosity $\left[\mathrm{cm}^{3} / 100 \mathrm{~cm}^{3}\right]$ & $73.3^{\mathrm{a}} \pm 0.4$ & $74.3^{\mathrm{a}} \pm 0.6$ & $74.3^{\mathrm{a}} \pm 0.5$ & $74.3^{\mathrm{a}} \pm 0.6$ & $73.9^{\mathrm{a}} \pm 0.5$ \\
\hline \multicolumn{6}{|l|}{ Crumb color } \\
\hline$L$ & $75.7^{\mathrm{c}} \pm 0.76$ & $69.75^{\mathrm{b}} \pm 0.47$ & $69.45^{\mathrm{b}} \pm 1.56$ & $68.19^{\mathrm{ab}} \pm 0.38$ & $67.31^{\mathrm{a}} \pm 0.62$ \\
\hline$a$ & $-0.69^{\mathrm{a}} \pm 0.05$ & $-0.51^{\mathrm{a}} \pm 0.14$ & $-0.35^{\mathrm{a}} \pm 0.29$ & $-0.40^{\mathrm{a}} \pm 0.42$ & $-0.37^{\mathrm{a}} \pm 0.34$ \\
\hline$b$ & $13.58^{\mathrm{c}} \pm 0.49$ & $12.53^{\mathrm{b}} \pm 0.48$ & $11.84^{\mathrm{ab}} \pm 0.19$ & $11.57^{\mathrm{a}} \pm 0.36$ & $11.01^{\mathrm{a}} \pm 0.34$ \\
\hline$\Delta E$ & - & $6.0^{\mathrm{a}} \pm 0.22$ & $6.5^{\mathrm{a}} \pm 0.37$ & $7.8^{\mathrm{b}} \pm 0.43$ & $8.73^{\mathrm{d}} \pm 0.45$ \\
\hline \multicolumn{6}{|l|}{ TPA } \\
\hline Hardness [N] & $12.99^{\mathrm{b}} \pm 0.64$ & $12.77^{\mathrm{b}} \pm 0.44$ & $11.15^{\mathrm{a}} \pm 0.59$ & $10.92^{\mathrm{a}} \pm 0.49$ & $11.25^{\mathrm{a}} \pm 0.49$ \\
\hline Springiness [-] & $0.94^{\mathrm{a}} \pm 0.01$ & $0.94^{\mathrm{a}} \pm 0.01$ & $0.95^{\mathrm{a}} \pm 0.01$ & $0.95^{\mathrm{a}} \pm 0.01$ & $0.94^{\mathrm{a}} \pm 0.01$ \\
\hline Cohesiveness [-] & $0.71^{\mathrm{a}} \pm 0.05$ & $0.66^{\mathrm{a}} \pm 0.03$ & $0.71^{\mathrm{a}} \pm 0.05$ & $0.71^{\mathrm{a}} \pm 0.01$ & $0.69^{\mathrm{a}} \pm 0.01$ \\
\hline Gumminess [N] & $9.07^{\mathrm{b}} \pm 0.73$ & $8.78^{\mathrm{b}} \pm 0.35$ & $7.86^{\mathrm{a}} \pm 0.09$ & $7.80^{\mathrm{a}} \pm 0.14$ & $7.82^{\mathrm{a}} \pm 0.28$ \\
\hline Chewiness $[\mathrm{N} \times \mathrm{mm}]$ & $9.04^{\mathrm{b}} \pm 0.24$ & $7.83^{\mathrm{a}} \pm 0.67$ & $7.45^{\mathrm{a}} \pm 0.09$ & $7.46^{\mathrm{a}} \pm 0.13$ & $7.31^{\mathrm{a}} \pm 0.57$ \\
\hline Water content $[\%]$ & $43.83^{\mathrm{a}} \pm 0.51$ & $43.59^{\mathrm{a}} \pm 0.33$ & $43.48^{\mathrm{a}} \pm 0.19$ & $43.79^{\mathrm{a}} \pm 0.16$ & $43.52^{\mathrm{a}} \pm 0.16$ \\
\hline Total protein content [\%] & $10.82^{\mathrm{a}} \pm 0.07$ & $11.20^{\mathrm{b}} \pm 0.01$ & $11.37^{\mathrm{b}} \pm 0.03$ & $11.77^{\mathrm{c}} \pm 0.07$ & $11.96^{\mathrm{d}} \pm 0.05$ \\
\hline Total ash content [\%] & $0.95^{\mathrm{a}} \pm 0.11$ & $1.10^{\mathrm{b}} \pm 0.02$ & $1.17^{\mathrm{c}} \pm 0.01$ & $1.27^{\mathfrak{c}} \pm 0.05$ & $1.34^{\mathrm{d}} \pm 0.02$ \\
\hline Total dietary fiber content [\%] & $3.58^{\mathrm{a}} \pm 0.11$ & $5.81^{\mathrm{b}} \pm 0.15$ & $6.03^{\mathrm{b}} \pm 0.15$ & $6.63^{\mathrm{c}} \pm 0.13$ & $7.19^{\mathrm{d}} \pm 0.17$ \\
\hline Total fat content $[\%]$ & $1.12^{\mathrm{a}} \pm 0.05$ & $1.54^{\mathrm{b}} \pm 0.02$ & $1.94^{\mathrm{c}} \pm 0.03$ & $2.34^{\mathrm{d}} \pm 0.03$ & $2.53^{\mathrm{e}} \pm 0.04$ \\
\hline \multicolumn{6}{|l|}{ The fatty acid profile [\%] } \\
\hline Palmitic acid & $15.70^{\mathrm{c}} \pm 0.40$ & $13.46^{\mathrm{b}} \pm 0.42$ & $13.14^{c} \pm 0.23$ & $12.33^{\mathrm{b}} \pm 0.35$ & $12.08^{\mathrm{a}} \pm 0.12$ \\
\hline Stearic acid & $1.67^{\mathrm{e}} \pm 0.10$ & $1.69^{\mathrm{d}} \pm 0.28$ & $1.76^{\mathrm{a}} \pm 0.16$ & $1.79^{\mathrm{a}} \pm 0.03$ & $1.82^{\mathrm{a}} \pm 0.16$ \\
\hline Oleic acid & $12.02^{\mathrm{a}} \pm 0.17$ & $13.19^{\mathrm{b}} \pm 0.10$ & $14.50^{c} \pm 0.34$ & $15.82^{\mathrm{d}} \pm 0.38$ & $16.31^{\mathrm{d}} \pm 0.25$ \\
\hline Linoleic acid & $67.98^{\mathrm{d}} \pm 0.38$ & $62.89^{c} \pm 0.59$ & $61.03^{\mathrm{b}} \pm 0.61$ & $59.36^{\mathrm{a}} \pm 0.76$ & $58.9^{a} \pm 0.76$ \\
\hline$\alpha$-Linolenic acid & $2.64^{\mathrm{a}} \pm 0.09$ & $8.77^{\mathrm{b}} \pm 0.38$ & $9.57^{\mathrm{c}} \pm 0.38$ & $10.69^{\mathrm{d}} \pm 0.87$ & $11.52^{\mathrm{d}} \pm 0.48$ \\
\hline \multicolumn{6}{|l|}{ Sensory evaluation } \\
\hline Appearance & $4.4^{\mathrm{b}} \pm 0.5$ & $4.3^{\mathrm{ab}} \pm 0.3$ & $4.3^{\mathrm{ab}} \pm 0.2$ & $4.2^{\mathrm{ab}} \pm 0.3$ & $3.8^{\mathrm{a}} \pm 0.3$ \\
\hline Taste & $4.3^{\mathrm{a}} \pm 0.2$ & $4.2^{\mathrm{a}} \pm 0.5$ & $4.3^{\mathrm{a}} \pm 0.3$ & $4.4^{\mathrm{a}} \pm 0.2$ & $4.1^{\mathrm{a}} \pm 0.3$ \\
\hline Smell & $4.5^{\mathrm{a}} \pm 0.2$ & $4.5^{\mathrm{a}} \pm 0.1$ & $4.6^{\mathrm{a}} \pm 0.2$ & $4.5^{\mathrm{a}} \pm 0.3$ & $4.0^{\mathrm{a}} \pm 0.3$ \\
\hline Color & $4.5^{\mathrm{b}} \pm 0.1$ & $4.3^{\mathrm{ab}} \pm 0.2$ & $4.3^{\mathrm{ab}} \pm 0.1$ & $4.0^{\mathrm{a}} \pm 0.4$ & $3.8^{\mathrm{a}} \pm 0.3$ \\
\hline Texture & $4.3^{\mathrm{b}} \pm 0.2$ & $4.3^{\mathrm{b}} \pm 0.1$ & $4.5^{\mathrm{b}} \pm 0.2$ & $4.5^{\mathrm{b}} \pm 0.3$ & $3.7^{\mathrm{a}} \pm 0.4$ \\
\hline Overall & $4.1^{\mathrm{a}} \pm 0.1$ & $4.2^{\mathrm{a}} \pm 0.2$ & $4.2^{\mathrm{a}} \pm 0.3$ & $4.0^{\mathrm{a}} \pm 0.2$ & $3.7^{\mathrm{b}} \pm 0.3$ \\
\hline TPC [mg GAE/g d.m.] & $0.44^{\mathrm{a}} \pm 0.02$ & $0.49^{\mathrm{b}} \pm 0.03$ & $0.61^{\mathrm{c}} \pm 0.03$ & $0.75^{\mathrm{d}} \pm 0.02$ & $0.82^{\mathrm{e}} \pm 0.04$ \\
\hline $\operatorname{ABTS}\left[\mathrm{EC}_{50}(\mathrm{mg} \mathrm{d} . \mathrm{m} . / \mathrm{ml})\right]$ & $959.1^{\mathrm{e}} \pm 43.6$ & $508.8^{\mathrm{d}} \pm 28.7$ & $415.6^{c} \pm 21.4$ & $296.1^{b} \pm 15.3$ & $186.4^{\mathrm{a}} \pm 10.3$ \\
\hline
\end{tabular}

${ }^{1} \mathrm{PK}$, control bread, CS2, CS4, CS6, and CS8, bread with 2, 4, 6, and $8 \%$ of chia seeds, respectively; the values are expressed as mean \pm SD; means with different letter superscript are significantly different $(\alpha=0.05)$.

described a similar trend, but it was not significant statistically.

3.5. Chemical Composition of Bread. The chemical composition of bread was shown in Table 3. There were no statistically significant differences in the content of water in bread samples. It ranged from $43.48 \%$ to $43.83 \%$. A high content of protein, ash, and dietary fiber in chia seeds contributed to an increase of the content of these components in the breads. The breads with the addition of CS were characterized by a significantly higher values of these components in comparison with the control sample. In CS8 bread the dietary fiber content increased twice as compared with the control sample. According to the World Health Organization (WHO) daily consumption of dietary fiber should amount to 30-40 g. Its presence in the human diet helps to accelerate intestinal peristalsis, reduces the absorption of cholesterol and triglycerides, decreases glucose levels in the blood, and reduces the feeling of hunger $[10,14]$. In addition, together with higher doses of chia seeds, there occurred an essential increase in the content of total fat. Thus, the addition of chia seeds to bread had a positive effect on nutritional values of the product. 
3.6. Fatty Acid Profile Analysis. The analysis of the fatty acid composition profile of the breads was showed in Table 3. In breads with the CS addition the content of saturated fatty acids (the sum of palmitic and stearic acids) ranged from $13.9 \% \mathrm{~g}$ to $15.15 \%$ and was lower than in the control bread (17.37). Generally, as the percentage of CS increased, the share of saturated fatty acid in bread decreased. The content of polyunsaturated fatty acids in bread with CS was at a similar level as in the control bread. The CS2, CS4, CS6, and CS8 samples had significantly higher content of $\alpha$-linolenic acid and lower content of linoleic acid than the control bread. The content of $\alpha$-linolenic acid in the bread has been rising according to the addition of chia seeds: approx. 3 times for CS2, 3.5 times for CS4, 4 times for CS6, and 4.4 times for CS8 as compared with the control bread. The obtained values are lower in comparison with the values obtained by Coelho and Salas-Mellado [10], who observed an increase of approx. 62 times in the acid content of $\alpha$-linolenic acid in bread with chia seeds.

In our study, there was observed a change in the ratio of linoleic acid (n-6) to $\alpha$-linolenic (n-3). For the control sample the ratio was $25 / 1$, whereas in case of CS2, CS4, CS6, and CS8 breads this ratio was average $7 / 1,6 / 1,5 / 1$, and 5/1, respectively. The high content of $n-3$ fatty acids in the diet provides many healthy benefits. It is essential for proper brain functions and has beneficial effects in cardiovascular diseases and in prevention of arthritis [33].

3.7. Total Phenolics Content, Antioxidant Activity, and Results of Bread Sensory Evaluation. Chia seeds are potential source of chlorogenic acid, caffeic acid, quercetin, myricetin, and kaempferol [6]. These antioxidants can protect heart and liver. In addition, they exhibit anticancer and antiaging properties [34]. Table 3 shows the total phenolics content (TPC) and the ability to neutralize the free radicals (ABTS). The CS4, CS6, and CS8 breads had a significantly higher TPC level than the other bread samples. Moreover, with the increase of CS in breads, the ability to neutralize free radicals also increased. Segura-Campos et al. [35] showed that the partial replacing of wheat flour by chia protein hydrolysates had no effect on the antioxidant activity of white bread. On the other hand, Costantini et al. [14] noticed that the addition of chia flour increased the total antioxidant capacity of wheat bread.

The results of sensory evaluation of breads were shown in Table 3. The appearance of breads was rated as suitable for good baked bread. There was no difference in taste and aroma of bread. In each case bread was tasty and had a specific aroma. The addition of chia seeds caused darkening of the bread crumb, but it was generally not negatively evaluated by the panelists. Only for CS8 samples the significantly lower notes for crumb colour were evaluated in comparison to control bread. The points marked for texture of crumb indicate that control bread and CS2, CS4, and CS6 breads were dry and did not crumble during cutting, with very high springiness. Only in the case of CS8 sample significantly lower note for texture was observed. In conclusion, points awarded for general desirability of the bread amounted to approx. 4, which indicates that the addition of CS up to $6 \%$ did not affect the final product acceptance.

\section{Conclusions}

The use of CS in the wheat bread recipe resulted in negative reduction of loaf volume, darker color of the crumb, positive reduction of hardness, gumminess, and chewiness of the bread crumb. The sensory evaluation showed that of CS up to $6 \%$ had no significant influence on bread quality. As compared to wheat flour, chia seeds contained approx. 2 times higher total protein content and approx. 8 times higher ash content, 13 times higher fiber content, and approx. 20 times higher fat content, which resulted in a higher content of these ingredients in the enriched bread. Furthermore, bread contained approx. 6 times more total phenolic compounds; thereby it exhibited approx. 10 times higher antioxidant activity. Particular attention must be drawn to an increase in the content of n-3 $\alpha$-linolenic acid, dietary fiber, and phenolic compounds. Bread with addition of chia seeds can be a good supplement to a daily diet, which usually lacks those ingredients and can be considered as functional foods which can provide health benefits beyond the traditional nutrients it contains. Besides, the results showed that the substitution of wheat flour with CS up to $6 \%$ showed acceptable sensory scores which were comparable to wheat bread.

\section{Disclosure}

The results of the manuscript were partially presented as an abstract at the 3rd International Conference on Food and Agricultural Engineering (ICFAE 2017), 10-12 May 2017, Budapest, Hungary.

\section{Conflicts of Interest}

The authors declare that there are no conflicts of interest regarding the publication of this paper.

\section{References}

[1] J. A. Vázquez-Ovando, J. G. Rosado-Rubio, L. A. Chel-Guerrero, and D. A. Betancur-Ancona, "Dry processing of chia (Salvia hispanica L.) flour: chemical characterization of fiber and protein," CYTA - Journal of Food, vol. 8, no. 2, pp. 117-127, 2010.

[2] M. R. Sandoval-Oliveros and O. Paredes-López, "Isolation and characterization of proteins from chia seeds (Salvia hispanica L.)," Journal of Agricultural and Food Chemistry, vol. 61, no. 1, pp. 193-201, 2013.

[3] M. I. Capitani, V. Spotorno, S. M. Nolasco, and M. C. Tomás, "Physicochemical and functional characterization of by-products from chia (Salvia hispanica L.) seeds of Argentina," LWTFood Science and Technology, vol. 45, no. 1, pp. 94-102, 2012.

[4] E. Reyes-Caudillo, A. Tecante, and M. A. Valdivia-López, "Dietary fibre content and antioxidant activity of phenolic compounds present in Mexican chia (Salvia hispanica L.) seeds," Food Chemistry, vol. 107, no. 2, pp. 656-663, 2008.

[5] V. Y. Ixtaina, S. M. Nolasco, and M. C. Tomás, "Physical properties of chia (Salvia hispanica L.) seeds," Industrial Crops and Products, vol. 28, no. 3, pp. 286-293, 2008.

[6] R. Ullah, M. Nadeem, A. Khalique et al., "Nutritional and therapeutic perspectives of Chia (Salvia hispanica L.): a review," 
Journal of Food Science and Technology, vol. 53, no. 4, pp. 17501758, 2016.

[7] V. A. Barrientos, A. Aguirre, and R. Borneo, "Chia (Salviahispanica L.) can be used to manufacture sugar-snap cookies with an improved nutritional value," International Journal of Fuzzy Systems, vol. 1, pp. 135-143.

[8] M. R. Oliveira, M. E. Novack, C. P. Santos, E. Kubota, and C. S. Da Rosa, "Evaluation of replacing wheat flour with chia flour (Salvia hispanica L.) in pasta," Semina: Ciências Agrárias, vol. 36, no. 4, pp. 2545-2553, 2015.

[9] E. Steffolani, E. de la Hera, G. Pérez, and M. Gómez, "Effect of Chia (Salvia hispanicaL) Addition on the Quality of GlutenFree Bread," Journal of Food Quality, vol. 37, no. 5, pp. 309-317, 2014.

[10] M. S. Coelho and M. D. L. M. Salas-Mellado, "Effects of substituting chia (Salvia hispanica L.) flour or seeds for wheat flour on the quality of the bread," LWT-Food Science and Technology, vol. 60, no. 2, pp. 729-736, 2015.

[11] M. Hrušková and I. Švec, "Chemical, rheological and bread characteristics of wheat flour influenced by different forms of chia (Salvia hispanica L.)," Emirates Journal of Food and Agriculture, vol. 27, no. 12, pp. 872-877, 2015.

[12] V. Zettel, A. Krämer, F. Hecker, and B. Hitzmann, "Influence of gel from ground chia (Salvia hispanica L.) for wheat bread production," European Food Research and Technology, vol. 240, no. 3, pp. 655-662, 2014.

[13] E. Iglesias-Puig and M. Haros, "Evaluation of performance of dough and bread incorporating chia (Salvia hispanica L.)," European Food Research and Technology, vol. 237, no. 6, pp. 865874, 2013.

[14] L. Costantini, L. Lukšič, R. Molinari et al., "Development of gluten-free bread using tartary buckwheat and chia flour rich in flavonoids and omega-3 fatty acids as ingredients," Food Chemistry, vol. 165, pp. 232-240, 2014.

[15] D. Dziki, "The crushing of wheat kernels and its consequence on the grinding process," Powder Technology, vol. 185, no. 2, pp. 181-186, 2008.

[16] "Determination of moisture content of cereal and cereal products (basic reference method)," ICC 109/1.

[17] "Determination of crude protein in cereals and cereal products of food and feed," ICC 105/2.

[18] "Determination of ash in cereal and cereal products," ICC 104/1.

[19] AOAC International, Official Methods of Analysis of AOAC International, vol. 1, 16th edition, 1997, Section 45.4.07, Method 985.29.

[20] "Cereals and cereal products - determination of total fat content," ICC 136.

[21] PN-EN ISO 12966-2, Animal and vegetable fats and oils - Gas chromatography of fatty acid methyl esters Part 2: Preparation of methyl esters of fatty acids, 2011.

[22] V. L. Singleton and J. A. Rossi, "Colorimetry of total phenolics with phosphomolybdicphosphotungstic acid reagents," American Journal of Enology and Viticulture, vol. 16, pp. 144-158, 1965.

[23] U. Gawlik-Dziki, M. Świeca, D. Dziki, B. Baraniak, J. Tomiło, and J. Czyz, "Quality and antioxidant properties of breads enriched with dry onion (Allium cepa L.) skin," Food Chemistry, vol. 138, no. 2-3, pp. 1621-1628, 2013.

[24] R. Re, N. Pellegrini, A. Proteggente, A. Pannala, M. Yang, and C. Rice-Evans, "Antioxidant activity applying an improved ABTS radical cation decolorization assay," Free Radical Biology \& Medicine, vol. 26, no. 9-10, pp. 1231-1237, 1999.
[25] T. Jakubczyk and T. Haber, Analysis of cereals and cereal products, SGGW-AR, Warsaw, Poland, 1983.

[26] E. Armero and C. Collar, "Texture properties of formulated wheat dough," Z. Lebensm. Unters. For, vol. 204, no. 2, pp. 136145, 1997.

[27] H. S. Muhimbula, A. Issa-Zacharia, and J. Kinabo, "Formulation and sensory evaluation of complementary foods from local, cheap and readily available cereals and legumes in Iringa, Tanzania," African Journal of Food Science, vol. 5, no. 1, pp. 2631, 2011.

[28] P. L. Pizarro, E. L. Almeida, N. C. Sammán, and Y. K. Chang, "Evaluation of whole chia (Salvia hispanica L.) flour and hydrogenated vegetable fat in pound cake," LWT-Food Science and Technology, vol. 54, no. 1, pp. 73-79, 2013.

[29] M. Á. Valdivia-López and A. Tecante, "Chia (Salvia hispanica): a review of native mexican seed and its nutritional and functional properties," Advances in Food and Nutrition Research, vol. 75, pp. 53-75, 2015.

[30] P. Marpalle, S. K. Sonawane, and S. S. Arya, "Effect of flaxseed flour addition on physicochemical and sensory properties of functional bread," LWT-Food Science and Technology, vol. 58, no. 2, pp. 614-619, 2014.

[31] M. C. Bourne, “Texture profile analysis," Food Technology, vol. 32, no. 7, pp. 62-72, 1978.

[32] D. Dziki, M. Siastala, J. Laskowski, and M. Siastała, "Evaluation of physical properties of trade bread," ActaAgrophysica, vol. 18, no. 2, pp. 235-244, 2011.

[33] P. L. Pizarro, E. L. Almeida, A. S. Coelho, N. C. Sammán, M. D. Hubinger, and Y. K. Chang, "Functional bread with n-3 alpha linolenic acid from whole chia (Salvia hispanica L.) flour," Journal of Food Science and Technology, vol. 52, no. 7, pp. 4475-4482, 2014.

[34] D. G. Kumar, P. C. Perumal, K. Kumar, S. Muthusami, and V. K. Gopalakrishnan, "Dietary evaluation, antioxidant and cytotoxic activity of crude extract from chia seeds (Salvia hispanica L.) against human prostate cancer cell line (PC-3)," International Journal of Pharmacognosy and Phytochemical Research, vol. 8, no. 8, pp. 1358-1362, 2016.

[35] M. R. Segura-Campos, I. M. Salazar-Vega, L. A. Chel-Guerrero, and D. A. Betancur-Ancona, "Biological potential of chia (Salvia hispanica L.) protein hydrolysates and their incorporation into functional foods," LWT-Food Science and Technology, vol. 50, no. 2, pp. 723-731, 2013. 

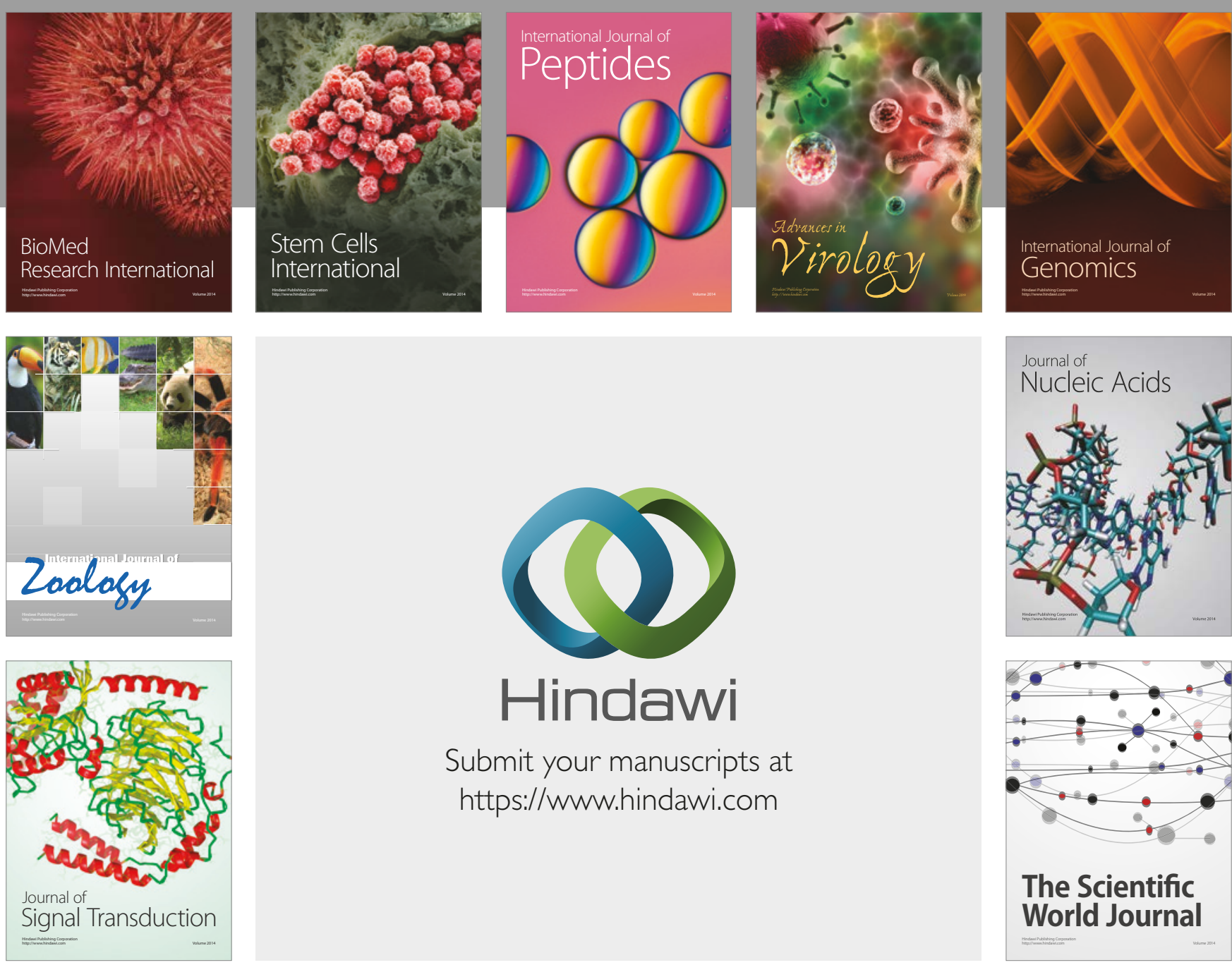

Submit your manuscripts at

https://www.hindawi.com
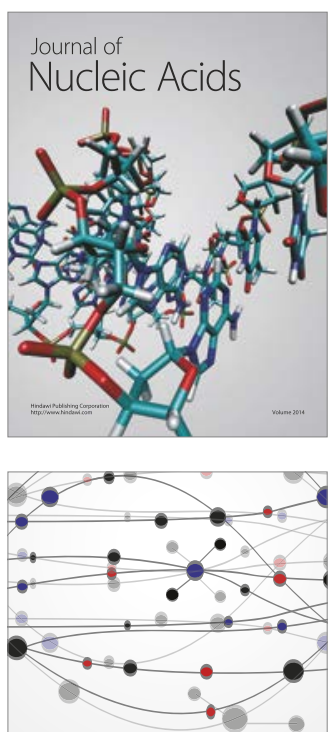

The Scientific World Journal

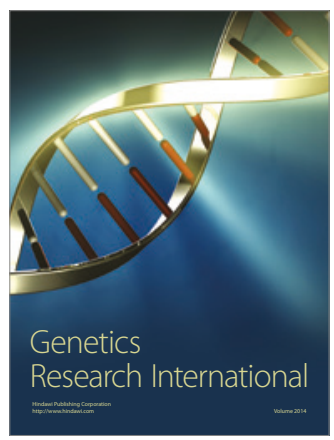

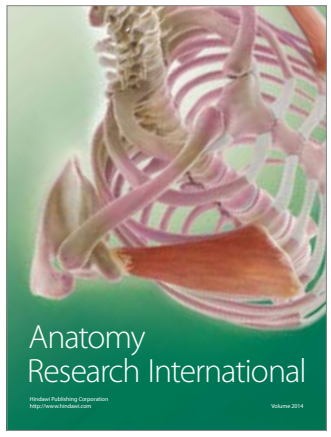

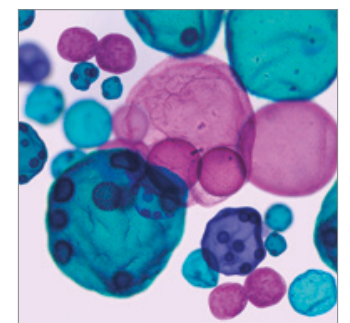

International Journal of Microbiology
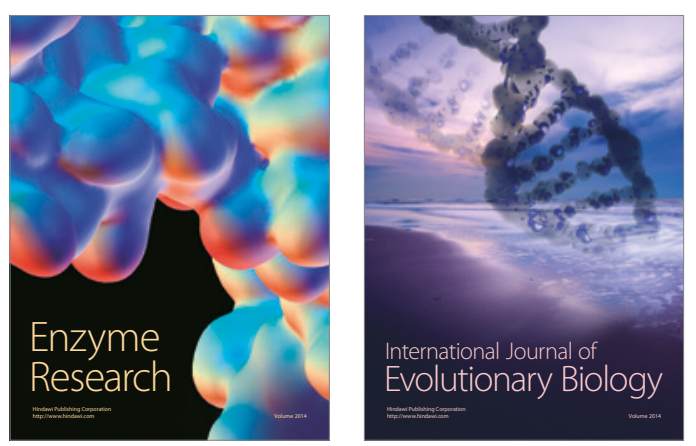
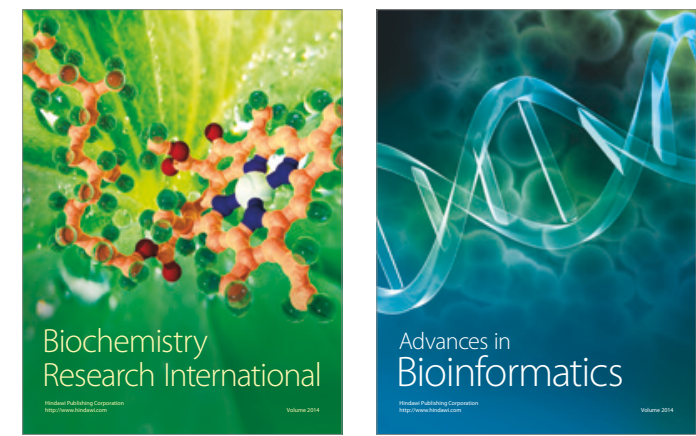

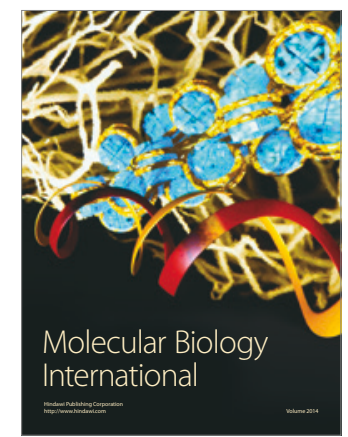

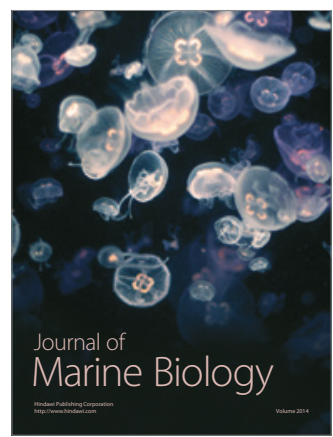

